\title{
The Basics of Event-Related Management of Safety and Quality in Economics
}

\author{
Evgeny Dmitrievich Solozhentsev \\ Honored Scientist of the Russian Federation, \\ St. Petersburg State University of Aerospace Instrumentation \\ Professor of the Institute of Business Technologies \\ URL: www.topeconomics; mail: esokar@gmail.com
}

\begin{abstract}
The work forms a new breakthrough scientific trend in the management of safety and quality in the economics based on the introduction of new objects and management criteria, new knowledge and models, new tasks, special software and digital management.

The paper offers the new management objects: State authorities, socioeconomic systems and projects, process quality management in the socio-economic life of a person, the safe living space. We use the management criteria of safety and quality.

The paper introduces the new knowledge for management in economics: the methodology of safety and quality, new types of Boolean events-propositions, scenarios of systems failure, new types of logical-probabilistic models, results of research of various systems and educational program.

New management tasks are also considered, special software are described and the essence of digital management in economics is stated.
\end{abstract}

Keywords: total safety management, managed objects, business enterprises, economics, safety and quality criteria, event-related digital management, structural complex systems, new knowledge and tasks, invalidity, special software.

\section{INTRODUCTION}

Many papers describe the unsatisfactory management of State and economics. Many economists are trying to find a way to overcome this critical situation.

The present theory of economic management is inadequate. A long time there are no fundamental achievements in State and economics management. Economics management is performed without mathematical methods and models on the basis of ephemeral concepts and aims, using "unwritten rules", "manual management", or "give me more money" principle, promises, ephemeral programs of economic growth and reviving industry.

After analysis of ephemeral management methods, management objects, State officials, army and policy structure, the education system, economic and academic sciences, a conclusion was made about impossibility to remedy the situation without a new outlook, new knowledge and new tasks in economics management.

The presented study outlines the scientific foundations of a new breakthrough trend in management of safety and quality in structural complex systems in economics.

Aim is the creation of a new breakthrough scientific trend in economics "Event-Related Management of Safety and Quality in Economics" on the basis of new knowledge and new tasks solution.

New objects and criteria of management are State authorities, socioeconomic systems and business activities, quality management of processes in the socioeconomic life of a person and the safe living space. Safety and quality of system have been selected as management criteria.

New knowledge. For management in economics the new knowledge are introduced: the methodological and methodical foundations of safety and quality management, new types of Boolean events-propositions, scenarios of systems failure, new types of logical-probabilistic (LP) models.

New tasks. For management in economics the new tasks are proposed: modeling, analysis and management of one system and a group of logically connected systems (models); management of the State and evolution of systems; assessment of management system quality.

Digital management in economics is defined as a technology of wide introduction of innovations and new tasks solution on the basis of the unified set of new knowledge, methods, models, tasks, technologies and software. Digital management has been connected with innovations and investments.

Scientific novelty. The new breakthrough scientific trend "Event-Related Management of Safety and Quality of Structural Complex Systems in Economics" is created. In management of economics we introduce: the methodological and methodical foundation, new objects and criteria of management, new knowledge and tasks, special software and the set of LP-models for the management of safety and quality of systems.

Practical value. We offered the way to overcome critical situations for economies and successful development. Authorities have to develop and use new knowledge and solve new tasks in economies. We have created the LP-models for the State analysis and management of economic systems under safety and quality criteria. Special software was adapted for management purposes. Additional education program for 
economists was developed. We proposed a unified system of knowledge, models, and software for event-related digital management.

Publications. We are engaged in research of eventrelated economic management for almost 20 years. We have published 8 books, including 3 books in English (Springer and Cambridge Scholars Publishing) and more than 30 papers, including 10 Scopus publications. Our results were presented and discussed at International Scientific Schools "Modeling and Analysis of Safety and Risk in Complex Systems" (MASR 2001-2016, SaintPetersburg, IPME RAS) and use in educational program of the State University of Aerospace Instrumentation.

The fundamentals of a new scientific trend were published in a large number of papers in Russian and English with the Scopus index in different years and were scattered for economists. Papers describe methodology of event-related digital management of systems, new objects and criterion, new knowledge and tasks, substantiations on digital management. In the paper, these results are brought together.

Concepts and statements of eminent scientists about management of economics. This study was performed for the first time. In development a scientific trend in economics, choice a mathematical apparatus and constructing risk models of systems, separate concepts, principles and statements of eminent scientists about management in economics were used.

Norbert Wiener and John von Neumann, the founders of cybernetics, believed that mathematical methods for management of socio-economic systems should be based on logic, set theory and combinatorics.

Albert Einstein, the famous scientist, wrote that no problem can be solved at the same level at which it arose.

Rudolf Kalman, the author of the Kalman's filter, believed that the problem "data à model, explaining data" should be considered as basic for any branch of science.

Nobel laureate James Buchanan considered the relationship of government, corruption and public opinion in the State.

Nobel laureate J. Heckman proposed an analytical apparatus of mathematical statistics for the analysis of socio-economic processes in the State.

The Nobel dynasty was guided by the principle of social justice. Nobel family spent a significant part of their profits for workers: they paid decent wages, built houses, kindergartens and schools, provided free medical services.

Li Keqiang, the Prime Minister of China, said, technological innovation and innovation in management are the same.

Kate Raworth, Professor at Oxford University, proposed a new economic model in the form of a "safe living space" ring (doughnut). Outside the ring - the ecological limits of the earth are violate: dangerous climate change, water pollution, etc. Inside the ring - the resources for a good life: food, clean water, housing, energy, education, etc. are lack.

Albrecht W., Wernz G., Williams T., American lawyers, believed that everyone was capable of fraud if circumstances put pressure and there is no sufficient control.

Isaac Newton, the great English scientist, believed that concrete examples are no less instructive than theory.

Williams Okkam, an English philosopher, believed, we should not complicate the model unnecessarily. A simple model is more likely to be correct. Sets and logic allow you to build the most simple and transparent models.

Robert Stevenson, an American scientist, believed that errors in projects (development programs) of complex systems and projects are inevitable and operational tests are necessary to identify and eliminate errors.

Stephen Robbins and Mary Coulter, authors of the textbook "Management", set out the components of system management, which include the functions of planning, organization, management and control, which can be the basis for assessment the quality of management systems in economics.

I. Ryabinin proposed the logical probabilistic calculus for reliability theory in structural complex systems in engineering [1]. We applied this theory to economic systems by introducing multi-states of the system instead of two states (refusal / failure) in technology.

N. Hovanov developed a method of randomized summary indicators for ranking systems and synthesis the probability of events by non-numerical, incomplete and inaccurate expert information, which is used to construct safety and quality LP models in economics [2].

The author defended his doctoral thesis in the USSR "Fundamentals of Building Systems for Automated Development of Complex Machines" (1983, Institute of Cybernetics, Academy of Sciences of Ukraine, Kiev) [3]. The theory and results of thesis are developed for management in economic systems.

\section{METHODOLOGICAL FOUNDATIONS OF MANAGEMENT IN ECONOMICS}

The fundamentals of a new scientific trend were published in a large number of papers with the Scopus index and were scattered for economists [4-8]. They include methodological foundations of event-related management of systems, new objects and criterion, new knowledge and tasks, substantiations on digital management. In the paper, these results are brought together, excluding some mathematical descriptions and limiting themselves to references.

We propose the methodological foundations of management of structural complex systems in economics, which are considered as new knowledge in management of economics. They are formulated in the form of provisions that we will consider as event-propositions and new knowledge in management. These provisions are common to all economies and states. To develop a new scientific trend "Event-Related Management of Safety and Quality in Economics", the following statements on management methodology in economics were proposed and used:

1. It is impossible to increase efficiency in economics without a new outlook, new knowledge and solving new tasks. 
2. All the troubles of the economics are caused by management.

3. Safety and quality are the prerequisites of existence of all systems. We propose to perform management in economics using safety and quality criteria.

4. New scientific tend in the management of safety and quality in economics should use new knowledge: methodological and methodical bases of management of economics, new Boolean event-proposition, risk scenarios for system failure, new risk models, new tasks, special software and assessment of the management systems quality.

5. New objects for management should be: public authorities, socio-economic systems, process quality management in the socio-economic life of a person and a safe living space. The management of these systems should be part of the management of the economics and the State.

6. To manage economics, system structure should be used - to introduce connections $A N D, O R, N O T$ between the elements of the system and the purpose of the system.

7. The management of systems (objects) in the economy should be carried out according to the scheme: modeling $\rightarrow$ analysis $\rightarrow$ management. Management on quality and safety criteria is carried with the participation of the manager.

8. The safety of the system is defined by the concepts of "risk" and "acceptable safety". The quality of the system is determined by the invalidity of system's indicators.

7. Consider management and optimization are close in meaning: optimization, according to safety and quality criteria, is management; management by criteria is optimization.

8. The model of invalidity should be built on the invalidity indicators of one state of the system.

9. Systems and their components should be associated with events and logical variables.

10. Consider internal events as factors of success/failure of management in economics are: theory and methods of management, objects of management, managers (officials), army, education system, economic and academic sciences.

11. Consider the management of the system's evolution as the management of the movement along the program trajectory at the stages and correction when deviating from it.

12. To manage the system in time for signal events with a correction of the probabilities of initiating events in LP-models of safety and quality.

13. Digital management is considered as a technology of wide and rapid introduction of new scientific trend in economics to solve important problems.

14. The technology of the digital management in economic systems increases their efficiency, safety and quality.

15. Accept the dialectic of the subjective and objective in invalidity: the system requirements are set subjectively, and the compliance of the system with these requirements is objective factor.
16. Calculate significances of initiating events and manage changes of the probabilities of these events, investing funds, improving staff skills, changing the structure of the system and performing reforms.

17. The system's management modeling in the economics found that without scientists and public opinion the problems of economics cannot be solved.

Boolean propositions were the basis for the creation of mathematical logic. They were developed in events in engineering and served as the basis for the theory of reliability. Boolean propositions are almost never used in economics.

The main requirements for any systems are their quality, efficiency and safety. Hence, a mathematical apparatus and models are needed to quantify the criteria for efficiency, safety and quality of systems. To the greatest extent, the apparatus of logical-probabilistic calculus is suitable for this, besides providing a unified approach to the calculation of these criteria in all objects and systems. System security is defined by the concepts of "risk" and "acceptable security", the quality of a system is determined by the invalidity of its indicative events, its effectiveness - by the mathematical expectation of the risk of loss of assets or by price of the system on the market.

Methodical bases of safety and quality management of structural complex systems in economics are formulated in the form of provisions that will be considered as eventpropositions and new knowledge in management.

1. Any database can be transformed into knowledge base in the form of a system of logical equations.

2. LP-analysis of safety and quality is transparent and this is the advantages of LP-models.

3. The LP-model of the invalidity (quality, safety) of any system can be always built on the basis of invalid indicators of its state, taking into account the indicators of the external and internal environment of functioning the system.

4. When constructing LP-model of system safety and quality, external and internal influencing factors should be separately identified. This will allow construct an accurate LP-model, combining several systems with a correct account of repeated external event factors.

5. Logical variables become dependent when they are placed into one logical function. Therefore, we must perform the orthogonalization of logical functions so that the terms in the logical function are independent.

6. For each system, the following safety and quality models should be consistently constructed: structural, logical and probabilistic models.

7. The problem is solved for any logical complexity of systems.

8. The dynamics of LP risk models is ensured by the correction of the probabilities of initiating events when signal events occur.

9. The connection of various systems should be ensured by correct consideration of repeated events included in the LP-models of safety and quality of systems.

10. It is necessary to control and analyze the ephemerality of internal initiating events and factors of success / 
failure of the management system in the economics.

11. The overcoming critical situation in economics and every system should be performed on the basis of new knowledge and the solution of new tasks.

12. In order to manage the safety and quality of every system (object), it is necessary to select successively: objects and criteria, new knowledge, LP-models, new tasks, LP-analysis methods for calculating contributions and significance of the initiating events, the technique of LP-management of system's state and system's evolution.

13. To estimate the quality of the management system on the LP-model.

14. Be informed with examples of computational research on safety and quality management.

15. Install special software Arbiter and Expa, having certificates, for modeling safety and quality.

16. Pass a licensed additional education program for economists in the management in economics.

17. Connect to the computer network event-related digital management.

18. To analyze the relationship of event-related digital management with innovations and investments.

19. Use the unified set of models, knowledge, tasks, and special software for event-relate management.

\section{THE EPHEMERAL MANAGEMENT IN ECONOMICS}

In managing economics, internal influencing eventsfactors of success/failure were identified: theory and methods of management, objects of management, managers (government officials), education system, economic and academic sciences.

Internal influencing events-factors of economics management in Russia were analyzed. All eventsfactors of management system are ephemeral, i.e. they are illusory phantoms. The following aspects of the economic safety of Russia continue to deteriorate: the national debt is growing, the scientific and technological potential is decreasing, the industrial foundations of the national economics are being destroyed, difference in income of various groups of population is growing very rapidly, finances are flowing out of the country, etc. We have performed the analysis of the ephemeral economic system of management in Russia in order to cope with the critical economic situation [4].

Management methods. Management use ephemeral concepts and targets, is based on promises and slogans, appeals, ephemeral programs of economic growth, increasing labor efficiency and industrial revival; management by "unwritten rules", "manual management", "give me more money" principle. This situation inevitably leads to corruption.

Objects of management include aims, objectives, processes in economics. A lot of factors are ephemeral: GDP, the share of machine building in industrial output, investment volume and expenses on science, percentage of GDP. Being taken together, these factors make the problem of management as multi-criteria one, which is impossible to decide. Each of these factors depends on lots of various other factors and is not a criterion itself. If we build the time series for such factors, we will not get an answer what and how we are going to manage.

State officials are called ephemeral due to the following reasons: there are 1,4 times more state officials for every 10,000 people in Russia than in developed countries and 2,5 times more than in the countries with the average level of economic development; the salary of state officials is 14-15 higher than employees with university degrees; the increase in the numbers and salaries of state officials did not make the economics more effective. Due to these reasons managers are not interested in changing management in economics.

The army and the police are called so because they are ephemeral as state officials due to their large strength, high salaries and pensions and low efficiency of their activities. So, army and police are not interested in changing management in economics.

The educational system. We have destroyed the industry-specific principle of education, which was used in the Soviet Union when the educational system served not the interests of particular people, but trained the specialists which the country really needed. School leavers chose the university according to personal preferences and they knew in what position and where they would work later. There was no hype about certain jobs. It was believed that the market itself will determine which universities are going to develop. Actually, it was not the market, but the universities administration, which had their own ideas about market demands. Every university started training future lawyers, economists and state officials. Universities earned money on education fees.

The economic science. The "homo economicus" model dominates at present. This is an autonomous individual who seeks only maximum self-interest. In order to simplify the analysis, political and social factors are not considered. However, the production of new products and services requires non-standard solutions based on cooperation. This presupposes the expansion of social links between employees and employers. By this way non-financial social risks are increased. The importance of social environment and the standard of living is increasing.

The academic science. The situation in the academic science is really dramatic. The science community has lost the unity; it looks like islands with very few connections between them. Complicated problems are not tackled. The science community is getting older. The gap between generations of researchers is becoming wider. We must create favorable conditions for researchers. Destruction of science will lead to the decay in education and to the problems with sustaining the present complex infrastructure and developing new technologies. Maninduced disasters will become a usual thing.

A way out from critical situation. Ephemeral theory and ephemeral management objects cannot change management in economics in Russia and other countries. The ephemeral state officials, army, the educational system are not interested to change the situation and science cannot do this [4]. 
System safety and quality requirements are the main conditions of surviving as a nation. The fate of Russia depends on the fate of the Russian science. The main problems of the Russian economic science include the clan system, plagiarism of dissertations and red tape. Applications for the grants of the Russian Foundation of Fundamental Research supporting the development of the new research area have been rejected for over 10 years. The papers submitted to leading economic journals have also been rejected under various pretexts, though during the same period 10 Scopus papers and 2 books devoted to this topic were published in abroad.

The fate of Russia depends on the emergence of new knowledge and tasks in economics [4-8]. Ephemeral methods and objects of management in economics are typical not only for Russia, but in other countries, as well. The difference lies in the fact that such components of the management system as state officials, army and policy, the educational system, economics and academic science are in satisfactory condition, which provides the leading technological position of these countries.

\section{THE ESSENCE OF EVENT-RELATED DIGITAL MANAGEMENT}

Studying a lot of literature sources, we found digital economic management has not been touched upon. This can be explained by the fact that there are no mathematical models in management of economics. Event-related digital management is based on new knowledge, LPmodels and corresponding software [9]. The introduction of digital management is necessary due to a number of reasons. Problems of management in economics are the most vital and widely spread both at the top level of management, and at the level of regions, cities and enterprises. Problems of management have a complex interdisciplinary character, novel mathematical tools and are characterized by the use of intellectual knowledge. Problems of management have a high arithmetic and logical computational complexity and cannot be solved without special software. Event-related digital system management in economics employs new knowledge, unified techniques, mathematical models and special Software $[4,9]$.

Digital management in economics is considered as a technology of wide and fast introduction of the new scientific trend for solution important problems of economics. Digital management provides system management based on new knowledge, LP-models of safety and quality, technologies and special software. Digital management has a single unified set of methods, models, new knowledge, new tasks, technologies and software.

Links between the digital management system, innovations and investments are illustrated in Fig. 1. Here 1,2,3-educational systems, economic and academic science; 4 - new knowledge and tasks; 5 - innovations for systems and management, 6 - management systems; 7 - systems in economics, including mining and selling raw materials; 8 -investments from systems.

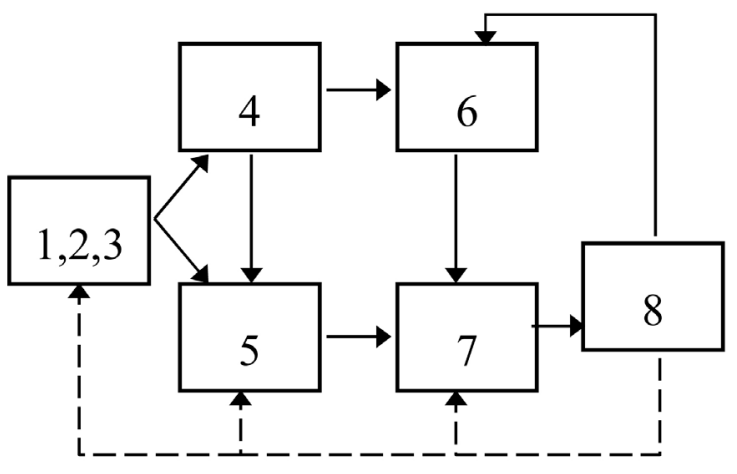

Fig. 1. The links between digital management, innovations and investments.

Specialists and investments are needed for the implementation of event-related digital management. The educational system trains specialists for systems, economic and academic sciences. The latter play a role in teaching students and develop new knowledge, innovations and technologies, improving the criteria of safety and quality of systems.

Investments derive from innovations in industry and system management. They are distributed for the education, economic and academic sciences; development of systems.

Digital economics and digital management. We had been conducting research in "Event-Related Management of Systems in Economics" more than ten years before the importance of developing "digital economics" was acknowledged nationwide. When "digital economics" had been acknowledged as the economic development technology, the place of the new scientific direction in digital economics was determined and its name was adjusted to "Event-Related Digital Management of Safety and Quality Systems in Economics". Due to the novelty of the research field, its complex character and computational complexity, there were practically no opportunities for large implementation. The situation changed when the government started support the development of digital economics.

\section{NEW OBJECTS OF MANAGEMENT IN ECONOMICS}

We study the following structural complex systems (objects) in economics $[4,9]$.

State authorities (in brackets - the number of objects): ministries (21), State agencies (35), services agencies (15), State corporations (2), State extra-budgetary funds (3), State Duma, Federation Council, governments and the legislative assemblies of the regions and cities.

Socioeconomic systems and projects. The State allocates the budget to socioeconomic systems (SES) and projects. The State incurs losses in SES and projects due to corruption, drug addiction, bribery, embezzlement, decisions taken by unwritten rules and not by law, excessive expenses on social and military projects. The SES groups can be identified:

Group SES-1 contains SESs with highest importance for the State, aimed at reducing the loss of funds and increasing revenues: management of innovations in the 
country, regions and companies, management of risk in banks and capital reservation by Basel III, management of production systems quality and product quality by WTO requirements, monitoring and management of crediting process in banks, opposition to bribery, corruption and drug addiction; assessment the management system quality.

Group SES-2 includes SESs which are complex for the State and the regions and depend on a number of ministries, departments and agencies (the systems of education, healthcare; agriculture, ecology, industry, communications, sport, transport, finances, economic development, energy).

Group SES-3 consists of the enterprises whose success depends mainly on their desires and capabilities. They include industrial, service, trade, transport, banking, educational, medical, etc. companies. In our papers we analyzed the management of risk and efficiency of a restaurant, management of crediting process in banks, etc.

Processes quality management in socio-economic life of a person. Such processes include: treatment of diseases, training at the institute, child care and others. A characteristic feature of these processes is the participation of several subjects and their respective infrastructures. For example, the process of cataract eye surgery is reviewed and analyzed with the aim of improving its quality. Management is performed according to the criterion of quality, taking into account the following event factors: 1) medical personnel qualifications and hospital infrastructure, 2) the patient's condition and the infrastructure outside the hospital in the postoperative period, 3) deficiencies in the organization of treatment in the State. Evaluation, analysis and quality management of a cataract surgery-treatment process is performed on event-related logical-probabilistic model. Structural, logical and probabilistic models of the quality of eye cataract surgery are built. The estimation of the probabilities of initiating event-factors is performed by the method of randomized summary indicators for nonnumeric, inaccurate and incomplete expert information by the method of statistical data identification on the results of surgery-treatment success.

Safe space of humanity. Kate Raworth from Oxford University notes: in the $21^{\text {th }}$ century the economics strived to be a science based on an erroneous picture of humanity [7]. The dominating model — "rational homo economicus", self-interested, isolated, calculating tells us more about economists than about common people. The loss of the goal encouraged the task of achieving permanent economic growth. Kate Raworth reconsiders the foundations of economy. She presents the economic model, which consists of two rings. If we go beyond the outer ring, we will leave the ecological limits of the Earth and face climate change, the depletion of the ozone layer and water pollution. If we go beyond the inner ring, we will not have enough resources for good life: food, clean water, accommodation, sanitary conditions, energy, education, healthcare and democracy.

\section{NEW KNOLEDGE IN MANAGEMENT IN ECONOMICS}

Methodological (19 concepts and positions) and methodical (19 definitions and solutions) foundations of management in economics were described earlier as new knowledge. The following new knowledge is also introduced for managing economics: Boolean utterance events, system failure scenarios, and LP risk models of systems.

Boolean events-propositions for management. The ideas of "events-propositions", which were developed in the works of G. Boole, P. Poretsky, S. Bernstein, A. Kolmogorov, V. Glivenko and I. Ryabinin, were elaborated further and extended. To manage the economics seven new types of Boolean events-propositions were introduced: about the failure of subjects and objects, signal events, invalidity events, conceptual and indicative events, latent and repeated events, groups of incompatible events [4-6].

The logical addition of events forms a derivative event. In management tasks in economics the probabilities of success / failure, danger / safety, validity / invalidity of events are used.

The system failure scenario is a description of events-propositions affecting system failure, as well as their logical connection with each other and system failure.

New types of system failure risk LP-models. For the purposes of system management in economics we use structuring, establishing logical connections $A N D$, $O R, N O T$ of the elements with each other and with the target of the system. Seven new types of safety and quality models were proposed and tested: hybrid models of system failure; invalid models of risk and quality; conceptual models of predicting system development; indicative models of system state danger, models used for management of system's state and evolution; models for system management quality assessment.

LP-risk models. LP-models should be used for comprehensive analysis and management of one system. Different systems are connected by repeated events-propositions. Criteria of safety and quality are management criteria.

Safety and quality criteria are simply calculated and analyzed on the probabilistic risk model obtained after orthogonalization of the logical risk model of the system. The problem is solved for any complexity of the logical model.

The dynamic character of the LP-model of systems is ensured by the correction of the probabilities of events - proposition for signal events, which indicate the necessity of changing the probabilities of initiating events in LP-models. The probabilities of probabilistic model are adjusted by non-numerical, inexact and incomplete expert information.

\section{THE NEW CRITERIA OF MANAGEMENT IN ECONOMICS}

Event management of the safety and quality of structural complex systems in economics is performed 
according to the criteria of safety and quality. Safety of a system is defined by the concepts of "risk" and "acceptable security", the quality of a system is determined by the invalidity of its indicator events, effectiveness of a system - by the mathematical expectation of the loss of assets or by market price of the system. The criteria of safety and quality have the following advantages $[4,5,9]$ :

1. Providing the main requirements for any systems - a quantitative assessment of the criteria of safety and quality.

2. Use for calculations and analysis the criteria of the known logical-probabilistic calculus.

3. The use of the methodological foundations for managing both the quality and safety of systems.

4. The use of a single unified approach for the construction and study of models of quality and safety for all structural complex systems in economics.

5. The possibility of combining any number of different systems (models) into one joint system (model) and solving new actual tasks in economics.

6. The possibility of creating the digital management of safety and quality in economics based on a unified set of knowledge, models, tasks and software.

7. The possibility of forming a new breakthrough scientific trend in economics and the economic sciences "Event-Related Management of Safety and Quality in Economics".

\section{NEW TASKS IN MANAGEMENT IN ECONOMICS}

New tasks are designed for:

- Theoretical forecasting and development of system evolution programs;

- Management of state and development of functioning systems;

- Operational management of systems in case of unexpected events.

With the designations: $M$ - modeling, $A$ - analysis, $C$ - management, the scheme of management process of the economic system in general form can be represented:

$$
\begin{gathered}
\left(M_{1} \rightarrow A_{1} \rightarrow C_{1}\right) \rightarrow\left(M_{2} \rightarrow A_{2} \rightarrow C_{2}\right) \rightarrow \ldots \rightarrow\left(M_{i} \rightarrow A_{i} \rightarrow\right. \\
\left.C_{i}\right) \rightarrow \ldots \rightarrow\left(M_{n} \rightarrow A_{n} \rightarrow C_{n}\right),
\end{gathered}
$$

where $i=1,2, \ldots, n$ are stages or management time.

The created and adapted Arbiter and Expa software systems allow solve following new and previously unknown management tasks in economics:

1) Modeling, analysis and management (MAM) of the safety and quality of one system;

2) MAM of safety and quality of several systems combined into one common system (logical model);

3) MAM on common logical model of safety and quality of systems connected by logical operations $O R, A N D$, NOT, with different outcomes;

4) MAM on common logical model of different systems with the correct account of repeated initiating events.

5) LP-management of system's state. We propose to perform the LP-management of the state of the systems, based on the quantitative LP-analysis of initiating events contributions in the following sequence: perform a quantitative risk analysis of initiating events contributions to safety and system risk, make decision about changing the probabilities of significant events, allocate resources to change probabilities of selected events, increasing staff experience.

6) LP-management of system's evolution $[3,8,14,15]$. We propose to perform management as a complex object control (Fig. 2). The system's movement is managed along the prescribed trajectory and corrections are made in case of deviations: $j=1,2, \ldots, n$ - stages of development; $R_{j}$ - criteria of safety or quality of the system, $U_{j}$ - managing actions (resources), $W_{j}-$ correcting actions (resources). A system is transferred from its initial state $A$ into the final state $B$ along the chosen trajectory $A-B$.

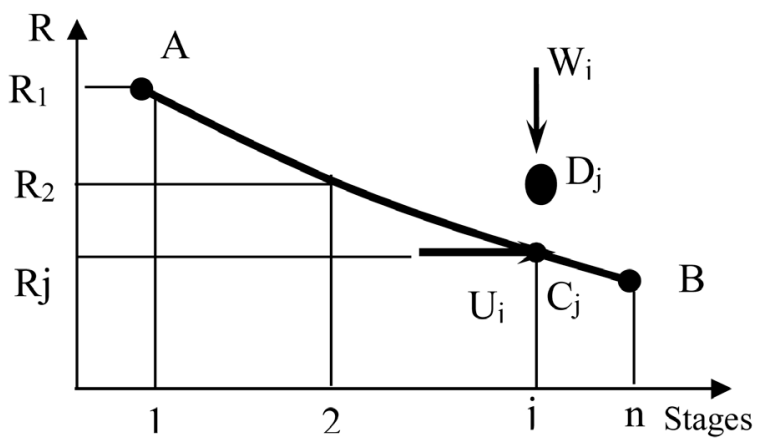

Fig. 2. Trajectory of system's evolution and control.

Structural, logical and probabilistic risk models are developed for a system. The criteria $R$ is calculated at each stage; contributions of events into system risk are analyzed. While developing the program of system's evolution management the values of $R, W, U$ at stages $n$ are determined. Resources are required for the realization of $R, W, U, n$. The LP-model of the process failure is built by the logical addition of failure at development stages.

7) The assessment of the quality of management systems in economics is made by the LP-model, built by the structural management model, which includes events-propositions about invalidity of the functions of planning, organization, management and control. Eventspropositions have a measure of invalidity in the interval $[0,1]$. Each function consists of events-propositions for sub-functions [16].

\section{SPECIAL SOFTWARE FOR MANAGEMENT IN ECONOMICS}

Systems in economics have a lot of events. The orthogonalization of the logical function of system risk for obtaining the probabilistic function of safety and quality for real systems is possible only with the help of special software. For the purposes of digital management of systems in economics the following special certified software can be used: Expa - for the synthesis of probabilities of events-propositions [17]; Arbiter - for structural logical modeling [18], as well as a licensed training course for further education of economists [19]. 
Works [8 - 15] provide about 30 examples of using software Arbiter and Expa for various objects and systems. The results of system management with real data helped us establish the following facts: socioeconomic problems cannot be solved without scientists and public opinion. To improve the efficiency of the country's innovation system, reforms in education, science and economics are needed.

\section{CONCLUSION}

The results of this study are follows:

1. The new breakthrough scientific trend in economics and economic science "Event-Related Management of Safety and Quality in Economics" is formed.

2. New objects (systems) of management in economics: public authorities, socio-economic systems, processes quality management of the socio-economic life of person, safe living space are introduced.

3. New knowledge for management in economics: methodological and methodical bases of safety and quality management, Boolean events-propositions, systems failure risk scenarios, LP-models of safety and quality of systems, examples of real systems management are introduced.

4. We offered the criteria of management in economics having some advantages.

5. New tasks in economics for modeling, analysis and management of one system and a group logically related systems (models) with different goals are offered.

6. The essence of the digital management of safety and quality of systems in economics is stated. The relationship of event-related digital management with innovations and investments is considered.

7. The special software Expa and Arbiter for safety and quality management in the economy are described.

\section{REFERENCES}

[1] Ryabinin I.A. Reliability and safety of structurally complex systems ( $2^{\text {nd }}$ ed). $-\mathrm{SPb}$.: Publishing House of St. Petersburg University. 2007. $276 \mathrm{p}$.

[2] Hovanov N., Yadaeva M., Hovanov K. Multicriteria Estimation of Probabilities on the Basis of Expert Non-numerical, Inexact and Incomplete Knowledge / European Journal of Operation Research. -Vol. 195. N 3. 2007, p. p. 857 - 863.

[3] Solozhentsev E. D. The Basics of Building a System of Automated Debugging of Complex Machine-Building Objects / Author's Summary of the Doctoral Thesis. Kiev: Ukraine Institute of Cybernetics, 1982.

[4] Solozhentsev E. D. Ephemeral and digital management of safety and quality in economics / Problems of risk analysis. Vol. 15, No. 5, 2018, p. p. 58-77.

[5] Solozhentsev E. D. The Management of Socioeconomic Safety. Cambridge Scholars Publishing, 2017. 255 p.

[6] Solozhentsev Eugene D. Top-economics. Economic safety management. - St. Petersburg: GUAP, 2015. 250 p.

[7] Raworth Kate. DOUGHNU ECONOMICS: Seven Ways to Think Like a $21^{\text {st }}$ - Century Economist. - Publisher: Cornerstone. Publication Date: 06.04. 2017. 284 p.

[8] Solozhentsev E. D.. Risk Management Technologies with Logic and Probabilistic Models.-Dordrecht, Heidelberg, New York, London: Springer. 2012, $328 \mathrm{p}$.

[9] Solozhentsev E. D. On the issue of digital management of state and economics. - Problems of risk analysis, Vol. 14, 2018, N 6, p. p. 39-43.

[10] Solozhentsev E. D. Top-economics: management of socioeconomic safety / Special Issue: Management of Safety in SocioEconomic Systems, Int. J. of Risk Assessment and Management, Vol. 21, 2018, Nos. 1/2. p. p. 65-88.

[11] Karasev Vasily, Solozhentsev Eugene. Hybrid logical and probabilistic models for management of socio-economic safety / Int. J. of Risk Assessment and Management, Vol. 21, 2018, Nos. $1 / 2$. p. p. $89-110$.

[12]. Solozhentsev E. D. Logic and probabilistic risk models for management of innovations system of country / Int. J. of Risk Assessment and Management. Vol.18. 2015, Nos.3/4. p. p.237-255

[13] Solozhentsev E. D., Mityagin S. A. Logic and probabilistic risk models for assessment and analysis of the drug addiction problem in a region / International J. of Risk Assessment and Management Vol. 18, 2015.No. 1, p. p. $1-20$.

[14] Solozhentsev E. D. I3-Technologies for Economics. - SPb.: Nauka, 2011, 386 p.

[15] Solojentsev Evgueni D. Scenario Logic and Probabilistic Management of risk in business and Engineering. Second Edition. - Springer. 2009. $450 \mathrm{p}$.

[16] Robins S. P., Coulter M. Management, 6-th edition. - M.: Williams Publishing House, 2002. $880 \mathrm{p}$.

[17] EXPA. Certificate of state registration of computer programs, No. 2018612197. Expert System Expa. Date of issue: February 13, 2018. Authors: E. Solozentsev, V. Alekseev, E. Karaseva.

[18] ARBITR. (PC ASM SZMA, basic version 1.0) certified for use at the facilities of Rostekhnadsor of the Russian Federation for a period of 10 years. Certification passport number 222 of February 21, 2007.

[19] License N 2556 of $09 / 05 / 2018$ for the implementation of educational activities issued by the Committee on Education by the Government of St. Petersburg to SPIK SZMA Joint-Stock Company (the course "Event-related digital management of safety and quality in economics" by E. Solozhentsev). 